\title{
Polyhydroxybutrate Production Using Groundnut Shell as Sulbstrate by Bacillus circulans (MTCC 8167) ${ }^{\dagger}$
}

\author{
Susithra K. ${ }^{1}$, Ramesh U. ${ }^{2}$, Kannan M. ${ }^{3}$, Varatharaju G. ${ }^{4}$, Premkumar G. ${ }^{1}$, Rajarathinam K. 1, \\ 1 Department of Botany., V.H.N. Senthikumara Nadar College (Autonomous), Virudhunagar - 626001 \\ 2 Department of Molecular Biology, School of Biological Sciences, Madurai Kamaraj University, Madurai - 625021 \\ 3 Department of Zoology, V.H.N. Senthikumara Nadar College (Autonomous), Virudhunagar - 626001 \\ 4 Department of Botany, Sri Kaliswari College (Autonomous), Sivakasi - 626123 \\ * Correspondence: krrathinam@yahoo.co.in; \\ $\dagger$ Presented at International e-Conference on Bioengineering for Health and Environment (ICBHE 2020)
}

Received: 5.07.2020; Revised: 10.07.2020; Accepted: 12.07.2020; Published: 15.07.2020

\begin{abstract}
Groundnut shell is considered to agro-industrial waste product and is rich in lignocellulose materials. It is obtained after the removal of groundnut seed from its pod and used as fodder for cattle. Duc et al., (2019) elaborately reviewed beneficial uses groundnut shells for commercial and industrial purposes and listed production of various bio-products such as biodiesel, bioethanol, and nano-sheet. The aim of this work was to study the production of polyhydroxy butyrate (PHB) using groundnut shells as the carbon source after hydrolysate. Groundnut shell was pre-treated with alkaline reagent with $0.5 \mathrm{M}$, $1 \mathrm{M}$, and $1.5 \mathrm{M}$, of potassium hydroxide and acid hydrolysis with $30 \%, 50 \%$, and $70 \%$, of sulphuric acid. Combined alkali (1M of potassium hydroxide) and acid (70\% sulphuric acid) pre-treatment of groundnut shell yield maximum reducing sugar. In addition, with pre-treated groundnut shell, various $\mathrm{pH}$ level $(6,7, \& 8), \mathrm{KH}_{2} \mathrm{PO}_{4}(100 \mathrm{mg} / \mathrm{l}, 200 \mathrm{mg} / \mathrm{l}$ and $300 \mathrm{mg} / \mathrm{l})$, and temperature $\left(25^{\circ} \mathrm{C}, 30^{\circ} \mathrm{C}\right.$ and $\left.35^{\circ} \mathrm{C}\right)$ are also test for PHB production. Bacillus circulans (MTCC 8167) significantly utilized the hydrolysate substrate and produced the maximum amount PHB $(7.6 \pm 0.2 \mathrm{~g} \mathrm{~L}-1)$ with $\mathrm{pH}$ level 7 and $30^{\circ} \mathrm{C}$ with $100 \mathrm{mg} / \mathrm{l}$ of $\mathrm{KH}_{2} \mathrm{PO}_{4}$. A detailed study of the functional group was also done using FTIR and NMR. Through biochemical pre-treatment, an in-expensive groundnut shell was converted into a valuable bioproduct in order to achieve the minimum waste production.
\end{abstract}

Keywords: Polyhydroxybutrate; Groundnut shell; Agro-industrial waste; lignocellulose.

(C) 2020 by the authors. This article is an open-access article distributed under the terms and conditions of the Creative Commons Attribution (CC BY) license (https://creativecommons.org/licenses/by/4.0/).

\section{Funding}

This research received no external funding.

\section{Acknowledgments}

This research has no acknowledgment.

\section{Conflicts of Interest}

The authors declare no conflict of interest. 